\title{
ON ENVATTMENT - DISJUNCTIVISM, SKEPTICAL SCENARIOS AND RATIONALITY
}

\author{
Giovanni Rolla* \\ rollagiovanni@gmail.com
}

RESUMO Este artigo tem dois objetivos: primeiramente, pretendese articular teses que são frequentemente avaliadas independentemente, mostrando com isso que uma versão robusta do disjuntivismo epistemológico sobre conhecimento perceptual implica uma concepção transformativa da racionalidade. Uma consequência disso é que indivíduos em cenários céticos não poderiam entreter pensamentos racionais sobre o ambiente em que habitam, pois eles não possuiriam estados perceptuais. Em segundo lugar, argumenta-se que a consequência delineada acima não é uma razão suficiente para rejeitar o disjuntivismo tal como apresentado. Esse argumento depende da avaliação de atribuições de racionalidade a indivíduos em casos plausíveis de ilusão e em alguns casos clínicos de alucinação.

Palavras-chave Cenários céticos, Disjuntivismo, Conceitualismo, Racionalidade, Alucinação, Ilusão.

ABSTRACT The aim of this paper is two-fold: first, it is intended to articulate theses that are often assessed independently, thus showing that a strong version of epistemological disjunctivism about perceptual knowledge implies a transformative conception of rationality. This entails that individuals in skeptical scenarios could not entertain rational thoughts about their

* Universidade Federal do Rio Grande do Sul. Artigo recebido em 09/06/2015 e aprovado em 15/09/2015.

KRITERION, Belo Horizonte, nº 134, Ago./2016, p. 525-544 
environment, for they would fail to have perceptual states. The secondary aim is to show that this consequence is not a sufficient reason to abandon the variety of disjunctivism presented. The argument for this claim depends on the assessment of rationality attributions to subjects in plausible cases of illusion and some clinical cases of hallucination.

Keywords Skeptical scenarios, Disjunctivism, Conceptualism, Rationality, Hallucination, Illusion.

\section{The transformative conception of rationality}

Commenting on McDowell's thesis that 'when we enjoy experience, conceptual capacities are drawn on in receptivity not exercised on some supposedly prior deliverance of receptivity’ (McDowell, 1994, Lecture I, \5), Boyle writes that

$[\ldots]$ an account of our sort of perceiving must itself appeal to capacities connected with rational thought and judgment. This is at least part of the significance of McDowell's well-known claim that the content of our perception is "conceptual": it amounts to the claim that the kinds of perceptual episodes which we rational creatures undergo must themselves be characterized in terms that imply the power to reason about the import of such episodes (Boyle, forthcoming).

The idea of a transformative conception of rationality, as advanced by Boyle, is that rationality is not something logically posterior to belief formation (and desire formation as well, but I will focus on the epistemological point). The competing views are called by Boyle 'additive theories', for they claim that rationality is to be added to the minimum 'animal' layer of cognition, which is passive, in the sense of lacking conceptual content. I will assume here the correctness of Boyle's criticisms of additive theories of rationality, that is, once we separate reason and its operations from a non-rational level of belief formation, we end up having to explain how exactly those two entirely different levels or capacities can be reconnected as a unity (the Unity Problem) and interact with each other (the Interaction Problem). ${ }^{1}$ If Boyle correctly

1 Kornblith's (2012) criticisms of the ideas that reflection is a necessary condition for knowledge (for a special kind of knowledge, namely, reflective knowledge), freedom, soundness of reasoning and normativity are based on the supposition that rationality can only operate in an additive way. He expresses the view he aims to attack as follows: 'my unreflective belief which simply registers the presence of the table, like my dog's unreflective belief which registers the presence of his food, is merely passive. But when I stop to reflect - something my dog cannot do - I become an agent with respect to my beliefs.' (ibid, p. 88, my italics). It 
identifies a transformative conception of rationality with conceptualism about perceptual experiences, I will also assume that conceptualism, at least broadly conceived, is correct. ${ }^{2}$

The transformative conception is essentially 'disjunctivistic', for it denies the existence of a common-kind level of cognition that is shared between our animality and the animality of (supposedly) non-rational animals, for, in our case, there is not a level of animality that is logically prior to the workings of our rationality. If, however, we are willing to say that other animals are also rational - for empirical evidence suggests that some are able to entertain complex beliefs and correct them with additional evidence ${ }^{3}$ - we can certainly say that they instantiate different levels of rationality, and that rationality admits a continuum of complexity, somewhere in which we fall. Nevertheless, we must notice that rationality in other animals may have developed differently in kind, as well as in degree, due to evolutionary demands, in a way that they may have different conceptual abilities and, consequently, different cognitions and interactions with the world. Consider the several kinds of fishes, some reptiles, and a few birds and mammals that are able to see the ultraviolet end of the color spectrum, thus perceiving the world significantly differently from the way we do. The young brown trout, for instance, is able to see UV rays for the practical purpose of mate choice (see Shi \& Yokoyama, 2003), something that could be quite useful for humans and would probably save a lot of time from divorce paperwork.

We can describe the transformative view as follows: our animality essentially contains (our) rationality. In a less metaphorical way, we can say that the perceptual states entertained by a person contain the actualization of her conceptual capacities. Since these capacities are what enable her to take a rational standing on her perceptual deliverances, rationality is already at work in her first-level thought about the world - equivalently: rationality is embedded in perception. Thus according to Boyle, if one rejects the myth of the Given - the idea that there is a non-conceptual element in our cognition

seems possible to evade at least some of Kornblith's criticisms by appealing to a transformative conception of rationality, which allows for the notion of epistemic agency in a way that is neither something posterior to belief acquisition nor freely choosing what to believe (which is the core idea behind doxastic voluntarism). Although I do have some reservations about conceptualism. See footnotes 7 and 8 bellow.

Kornblith (ibid, pp. 51-52) mentions the case of the piping plover, a bird that feigns to have a broken wing when it perceives a predator surrounding its nest. The feigning is used to lure the predator away from the bird's offspring - and as soon as it reaches a safe distance, it flies back to the nest. What is especially interesting is that the piping plover is able to recognize persons and animals as nonthreatening once they pass nearby the nest several times without trying to attack - thus changing its behavior. We can read this example as evidence that some animals are entirely capable of learning something through induction, thus apparently sharing a cognitive ability with us. 
that plays the role of foundational knowledge that justifies our higher-level knowledge, as McDowell (1994) explicitly does following Sellars (1997) - one is already committed to a transformative view of rationality. In what follows I will explore the logical relation this kind of view holds (or may hold, depending on varying intuitions and different construals) with another disjunctivist view, namely, disjunctivism about perceptual knowledge, in order to assess a particular consequence of conjoining these theses. ${ }^{4}$

\section{Epistemological disjunctivism and conceptualism}

Here I will assume not only a transformative view of rationality, but also a strong version of disjunctivism about perceptual knowledge. Disjunctivism about perceptual knowledge is the thesis that there is nothing epistemically common between paradigmatic cases of perception and the equivalent bad cases of illusion, hallucination or envattment (i.e., being a brain in a vat), for in paradigmatic cases of perception, the exercise of perceptive capacities delivers factive results. That is, in these cases, perceiving that P implies P. I take it that qualifying cases of perception as paradigmatic is a way to bracket bad objective and subjective conditions, which means that, in a paradigmatic case of perception, there is no trickery involved, one is not in a Gettier-style case, one's cognitive apparatuses are working properly, and one is rightfully unaware of any undefeated defeater of one's perceptual beliefs. ${ }^{5}$ The import of this thesis to our present discussion is the modus tollens it offers: given that perception that $\mathrm{P}$ (in paradigmatic cases) implies $\mathrm{P}$ and given that when one is in an equivalent bad case, say, hallucinating $\mathrm{P}$, one is not entertaining a factive experience, one is not having a perceptual experience.

It could be argued, however, that all the modus tollens above succeeds to show is the following: when one is hallucinating that $\mathrm{P}$, one is not in a paradigmatic case of perception, but one is still in a case of perception, a bad one. This route is available only insofar it is assumed that there is something epistemically common between paradigmatic cases of perception and the

4 Although I will not address the well-known objection that conceptualism is an overly intellectualist view on how we form our beliefs, I would like to remark that the temptation to quickly dismiss a transformative conception on such basis may arise from a confusion: as I interpret it, this view does not say that a subject must be conscious of the specific concepts she applies to her experience. It's actually the other way around: it is precisely because her perceptual beliefs are conceptualized that she can highlight those contents in a conscious experience.

5 To be sure, it does seem contentious to talk about 'rightful unawareness', for phrases like these seem to imply some sort of deontology, the idea that a subject has a 'right to believe'. I will not comment on this further, but I do think it may be a problem for disjunctivists. 
equivalent bad cases, lessening considerably the strength of epistemological disjunctivism. For this reading of the argument implies a common level yet to be determined between paradigmatically perceiving something and hallucinating something, and it assumes that this level is epistemically relevant, being more than a merely general kind such as 'being in a mental state'. In short, this reading of the argument denies a difference in kind, but accepts a qualitative difference between paradigmatic cases of perception and the relevant bad cases. Henceforth, I will assume the stronger version of disjunctivism I stated above.

It seems we could settle with the conclusion that paradigmatic cases of perception are factive, hence advocating a merely externalist variation of disjunctivism. But this is not what Pritchard does, for instance, when he claims that disjunctivism is able to save both externalists and internalist intuitions (Cf. Pritchard, 2012, pp. 3-4), in the precise sense that, according to the disjunctivist, whatever turns a true perceptual belief into knowledge is accessible to one, enabling one to know that one knows, through reflection or introspection, whenever one perceptually knows something. ${ }^{6}$ This means that one can know reflectively that one is in a paradigmatic case of perception, thus in a case of knowledge, whenever one is indeed in such a case. If we add to that the idea that one must, at least, be able to access one's epistemic credentials in order to achieve knowledge - a condition of reflexivity - then conceptualism seems unavoidable. The reason for this is that, if the contents of one's perception were not conceptual in nature, one would not be able to take them into a conceptual articulation, thus bringing it about as a source of epistemic justification that is sufficient for perceptual knowledge. To such an extent that disjunctivism aims to please internalism, as well as externalism, conceptualism is entailed. ${ }^{7}$

6 Pritchard applies a distinction here, according to which reflection is understood as introspection plus a priori reasoning (Cf. 2012, p. 123), but I will use these two terms interchangeably, in part because it is not clear what he means by 'a priori reasoning', in part because this distinction is especially needed to avoid the indistinguishability problem, that is, the problem of explaining why we can know that we know in paradigmatic cases of perception and cannot do so in the equivalent bad cases, supposing that they are phenomenologically identical for the subject. This problem arises only if we assume there is a shared level between perception in paradigmatic cases and the relevant bad ones, in a way that the variation of disjunctivism I defend here is able to avoid - a view that could be labeled as phenomenological disjunctivism, similar to the one defended by Martin (2006). The escalating commitment to disjunctivism on different levels is what I call 'disjunctivitis'.

7 However, I admit, this question is far from settled. One could argue that perceptual experience is nonconceptual in nature, but is conceptualized in the act of being articulated as reasons for believing. If this is the case, one could be an internalist without being a conceptualist. Although I fail to make complete sense of what would be the criteria for the conceptualization of something that is non-conceptual, I take this to be a possible position. That is not to say that the puzzle I present in this paper would not arise. True, it would not arise from disjunctivism per se, but that envatted brains could not be rational follows from disjunctivism and 
Brewer (2003, chapter 3) offers the following argument for the idea that perception must be conceptually articulated in reason-giving relations (enabling deductive and inductive inferences) in order for particular episodes of perception to serve as rational bases of belief formation. If perception determines the contents of beliefs about a mind-independent world for a subject, then necessarily perception has to be articulated in reason-giving relations, i.e., conceptually, otherwise the subject would have no reason to hold a particular belief that $\mathrm{P}$ about her surroundings instead of any belief $\mathrm{X}$, which means that perception would not contribute to the content determination of her beliefs. In other words, if perception provided us with a non-conceptual given, then its occurrences would not be able to serve as reasons for our particular beliefs about the world. This argument represents an attack on the myth of the Given, something even a modest account of internalism has to concede if it aims to defend the idea that one's perceptual knowledge is rationally founded.

So far we have seen that a version of epistemological disjunctivism that aims to please internalist intuitions, as well as externalist ones, implies the rejection of the myth of the Given, i.e., it implies a conceptualist view on the contents of perceptual experiences. ${ }^{8}$ This is a trait of internalist views in general, but it is plainly compatible with externalism about knowledge as well. Externalists claim one can know that $\mathrm{P}$ without knowledge of (or access to) the credentials of one's knowledge that $\mathrm{P}$ - but most externalists would happily agree that one can perceptually know that $\mathrm{P}$ and have good reasons to believe that $\mathrm{P}$, thus acquiring some sort of reflective knowledge. ${ }^{9}$ What externalists would deny is that rationally founded belief is a necessary condition for knowledge in general. However, if they accept the possibility of having a belief that is rationally justified in experience, they must accept that contents of perceptual experiences are at least conceptualizable, which is

conceptualism taken together - it is a problem for those who hold both views, for instance, McDowell (see below).

8 This commitment can be avoided by appealing to a non-conceptual construal of the notion of reasons, as does Peacocke $(1989,1992)$. However, if a reason $R$ is to be a reason for a subject $S$, then $R$ must be accessible to $S$, which implies that $S$ must be able to recognize $R$ as a reason, otherwise $S$ would be subjectively unjustified in holding a propositional attitude based on R. I will assume without arguing further that reasons are conceptual in nature, for it is way beyond the scope of this paper to have a definite position in the debate between conceptualists and non-conceptualists on this subject matter, but I do think it lessens the burden of the conceptualist view to hold that $\mathrm{R}$ may serve as a reason for a subject if she is able to successfully engage in certain activities by accepting $R$. The conceptualist view entailed by disjunctivism, therefore, is not uncontentious (see also footnote 7 above), and, although I am not aiming to defend it here, it seems that some disjunctivists must do so, insofar as they are committed to it.

9 With the notable exception of Nozick's tracking theory (1981), which is externalist in its core, but is incompatible with the acquisition of reflective knowledge of the form 'I know that my belief that P is true'. 
hardly disputable. At the limit, an externalist can accept the conceptual nature of perceptual experiences and deny that the credentials of such experiences are directly, immediately or inevitably imposed on first-order thought, thus allowing for the possibility that one perceptually knows that $\mathrm{P}$ without knowing or accessing the credentials of one's first-order knowledge. My point here is: as long as the factivity of perceptual experiences is the sole externalist contribution to disjunctivism, our view is exempt of conflict.

It is worth pointing out that some varieties of conceptualism are committed to epistemological disjunctivism as well. McDowell $(1994,2011)$ famously championed both views. In "Singular Thought and the Extent of Inner Space" (1998), he endorses the Russellian idea of singular thought, a thought that could not be entertained in the absence of its referents, and rejects the sense-data constraint, according to which one could only genuinely refer to subjective entities that are immune to Cartesian doubt. The connection with disjunctivism becomes clear if we note that there is nothing semantically common to cases of successful singular reference and non-referring thoughts, as Fregean scheingedanken, for singular thoughts refer non-descriptively. In other words, there is no semantic common factor between genuine reference and the relevant bad cases wherein a subject fails to refer because she is not presented to an object. To be sure, disjunctivism is not an inevitable corollary of conceptualism per se, but it does follow from the role played by nondescriptive conceptual reference and the idea that such reference essentially provides the reasons for beliefs about a mind-independent world. ${ }^{10}$ Even if this view on reference is untenable, if one is willing to defend it, one has to defend disjunctivism as well.

It is possible to defend an equivalence between a strong form of epistemological disjunctivism about perceptual knowledge and a specific conceptualist view on perceptual content. Henceforth, however, I will only assess one way of the arrow: if disjunctivism about perceptual knowledge

10 Brewer (2003) holds a similar view on his extensive articulation of key conceptualist ideas. According to him, the perceptual experiences entertained by a subject about a mind-independent world directly provide the reasons for her beliefs about the world. It is central to his view that reference to external objects in a mind-independent world is fundamentally non-descriptive, i.e., demonstrative. The reason for this is that only demonstrative reference can rule out the possibility of massive reduplication (2003, chapter 2$)$. The argument (known as 'Strawson argument') runs like this: if our reference to objects in a mind-independent world were exclusively descriptive, then we would be unable to rule the logical possibility that, for each object presently perceived, there is a qualitatively identical object somewhere else in the universe which satisfies the same descriptions we employed while trying to refer to a presently perceived object. Consequently, we would be unable to know that we successfully refer to any external object inhabiting a mind-independent world. However, given that we do know that we do successfully refer to such objects, we must reject the premise that our reference is exclusively descriptive. 
implies a conceptualist view on the contents of perceptual experience, for it aims to save internalist intuitions; and if Boyle is correct in saying that the denial of the Given is equivalent to a transformative conception of rationality, then disjunctivism about perceptual knowledge implies a transformative conception of rationality. In other words, according to the version of disjunctivism I am adopting here, rationality is a constituent of perceptual states as the actualization of conceptual capacities.

Now, imagine that I look at a goldfinch yonder while I am writing this paper. Imagine this happens several days in a row, and that sometimes I see more than one goldfinch in the trees (suppose, of course, that my perception is delivering the right results and that there is no trickery involved). I then come to believe, quite rationally, that there are goldfinches around here this time of the year. Imagine now (as the story generally goes) that my counterpart in a vat in Alpha Centauri is receiving similar stimuli and entertaining false beliefs about its surroundings. Imagine it comes to the same conclusion, which, despite its falsity, seems rational. If there is nothing epistemically common between a paradigmatic case of perceptual knowledge and a case of envattment, and irrationality is an essential constituent of perceptual experiences, in the sense that it operates in perception as the actualization of conceptual capacities, then when one is not in a perceptual state, one's conceptual capacities are not actualized and one is deprived of rational thought. Therefore, in the scenario just described, I am the only one being rational, while my envatted counterpart lacks rationality. It follows, more generally, that envatted brains not only fail to have perceptual states, they could not hold rational thoughts about their environment. ${ }^{11}$ And this seems outrageous!

In what follows, I want to dissolve the temptation to understand this conclusion as a reductio ad absurdum of at least one of its premises. One possible solution is to adopt a weaker version of disjunctivism according to which individuals in vat environments do share some general epistemic level with individuals entertaining genuine perceptive states, which implies that brains in a vat are rational despite the lack of factive perceptual states. But

11 Is there any other kind of rationality that brains in vats could manifest? It seems plausible that they could at least perform mathematical and abstract inferences successfully. Brains in vats could also run, say, Cogitolike thoughts: a kind of thought that is immune to the vagaries of the external world. But then again, would it be rational to think such idle thoughts? One could argue that a particular thought can only be rational if it has an actual, future or possible relevance for action and engagement with the world, something that Cogito-like thoughts and pure mathematical and abstract inferences seem to lack. I will not discuss here other forms of rationality - whether they exist depends on accepting the distinction between practical and theoretical rationality. Moreover, even if we accept that there is some sort of a priori or exclusively theoretical rationality, the main problem I discuss on this text remains: brains in vats could not entertain rational thoughts about their environment. 
this is not an alternative I will endorse, as I stated above. Moreover, I do think that the stronger version of disjunctivism about perceptual knowledge, albeit extremely unpopular until not long ago, enjoys some intuitive appeal. On the other hand, if the adoption of a transformative view on rationality is equivalent to the denial of the Given, then to reject a transformative view has a high price.

\section{Cases of unvattment}

The temptation to ascribe rationality to envatted brains is in part due to the idea that coherence is sufficient to rational thinking, an idea in clear conflict with the factivity of rationality (for a set of false beliefs can be coherent). Given the precedent results, it seems unlikely that even coherence can be properly ascribed to an envatted brain, if we assume, as it is reasonable to assume, that coherence is a property of sets of propositional attitudes, and that propositions are at least partially conceptually articulated. Moreover, a crude coherentism like this is not far from an additive conception of rationality, for it can be read as saying that there is a datum, a body of beliefs upon which it is expected from the individual to acquire coherence or at least to avoid inconsistencies. This second level effort of maintaining coherence is the idea that rationality operates separately from first-order belief acquisition, although rationality would influence which perceptually acquired beliefs are to be endorsed in order to maintain coherence intact.

One way out of the puzzle is to hold that envatted brains are not rational, in the sense that they do not actualize their capacities of applying concepts in their deviant experiences, but they are still rational in a weaker sense, for they still have those capacities at hand (or at brain). Let us give voice to this idea and imagine a case of unvattment, that is, a case in which a bodyless brain in a vat raised in Alpha Centauri is brought to Earth and is surgically put into a brainless body. This kind of case is intended to show not only that an unvatted brain can acquire perceptual knowledge like the rest of us, but, more importantly, that the unvatted brain's capacities were left intact while it was in the vat, in a way that it can eventually actualize those capacities in everyday thinking and perceiving just as we do. So, not only the brain can be rational once it is out of the vat and into a body, it was rational before that. This is a considerable objection.

The objection fails. Firstly, so presented, the case of unvattment seems underdescribed, for it is not clear whether an unvatted brain would manifest 
the same perceptual states as ourselves. ${ }^{12}$ Take for instance the clinical cases of experiential blindness, wherein individuals receive sensory stimuli but lack the understanding of how to integrate those stimuli in a genuine experience (cf. Noë, 2004, chapter 1). In a plausible interpretation, individuals that suffer from experiential blindness - say, patients recovering from cataract surgery - lack the conceptual abilities to transform simple stimuli into genuine experience. An unvatted brain seems to be in a similar predicament, since it would undergo a change from the absence of perceptual states to the presence of sensory stimuli, but it would, ex-hypothesis, lack the historic of interactions with the world that is essential for rationality. Secondly, the case presented above involves the controversial supposition that a capacity that has never been exercised is a capacity for something. Would we say that I am capable of piloting a fighter aircraft? I have never even been near one. But in a way I am not entirely incapable - if I had been born with the required skills, if I were a trained pilot, maybe if I were not such a lousy Sunday driver, and so on. But this amounts to saying that, if things were completely different, I would be capable. The same thing goes for the unvatted brain: if it were in a completely different situation, it would be rational. This claim shows us nothing. And finally, that answer to the puzzle about the lack of rationality of brains in vats lessens the idea that rationality is the actualization of conceptual capacities. This means that rationality would be at least partially additive, something that comes into play in a way that is logically independent of belief formation - a way out that is not open to the die-hard disjunctivist.

Our interlocutor could try to reply by describing a slow-switching case, as the ones introduced by Burge (1988) in the debate between externalists and internalists about mental content and self-knowledge. The case would work like this: consider an individual that was born in a normal environment on Earth and is normally connected to her body for an extended period of time. Somehow her brain is transported to a vat in Alpha Centauri without her knowledge of it. There, our interlocutor grants, her capacities are not being actualized while she entertains deviant experiences that fall short of genuine

12 It is possible to hold that envatted brains do have perceptual states, although those states are fundamentally different from ours. Combined with the transformative view of rationality, it would follow that we and the individuals in skeptical scenarios instantiate different forms of rationality - so the core of my argument would still stand, for there would be an incommensurability between their rationality and ours. Note also that this view would be on the spirit of Putnam's externalism about mental content (Putnam, 1981, chapter 1). One could, therefore, hold that brains in vats have perceptual states that are, in a way, factive, despite being intentionally opaque. Therefore, if this view is correct, skeptical scenarios would trivially fail to show that one could be a rational individual despite lacking perceptual states. This is a fascinating hypothesis, and I am indebted to an anonymous referee for pointing that out, but I will not pursue it here. It does remain an open possibility for future inquiry. 
cases of perception, but those conceptual capacities are still present for a while - she certainly did not lose them all at once. The argument goes: if she were brought back home after some time in the vat, we would surely say that she was still capable of being rational. And if this kind of case is committed to an additive conception of rationality, it is all too bad for transformative views.

Now, it is controversial whether individuals in slow-switching scenarios would retain their conceptual abilities, for this kind of case seems to be like a simple case of unvattment: from body to vat, from vat to body. How are we to be sure that the individual retains her abilities during these transitions? If sufficient time has passed while she was in the vat, it is not unreasonable to suppose she lost the abilities acquired on Earth. It only makes sense to suppose she is rational if we also suppose she learnt again how to operate with the received stimuli. Imagine that I learnt to play the guitar when I was a teenager and that I never played it again, as it is indeed the case. If I tried today, I would face quite a few difficulties: I would not remember most chords, my hands would be too slow, I would miss the strings too frequently, the melody would stammer. Would we say I am still capable of playing the guitar nowadays? And what would happen if I lost my hands and got them replaced? I would only be capable of playing if I learnt it all over. Moreover, whatever the answer we give here, it seems to be secondary, for this argument reaches a dead end. Not because slow-switching cases are logically impossible - they certainly are logically possible, and maybe only that - but because the fiction of thinking about brains in vats relies on an undue extrapolation of normal cases of mistake and deception, something that causes our intuitions to become fuzzy or, in the worst case, unreliable. I am not saying philosophical intuitions are generally unreliable or that they show us nothing. Our case here is more specific: something in the construction of a skeptical scenario goes amiss, and in what follows I will try to specify what it is.

\section{Hallucinations, illusions and ascriptions of rationality}

In contemporary epistemological debates, skeptical conclusions arise from arguments in which epistemic principles operate - such as the closure principle for knowledge (or justification) and the underdetermination principle. I will not focus on such principles here. Instead, I will sketch a solution to the puzzle about the rationality (or lack thereof) of envatted brains that hinges on questioning the legitimacy of skeptical scenarios. If this answer is correct, it may be a good starting point to undermine skeptical conclusions in general, but I will not explore this possible upshot here. 
First of all, skeptical scenarios are based on the possibility of error, as it is well known. But skeptical conclusions cannot arise from the mere observation that we know that sometimes we make perceptual mistakes, for this would directly undermine any sort of general skepticism, i.e., the claim that is possible that all our putative episodes of knowledge are cases of deception. This generalization depends on the evaluation of error episodes, and cases of illusion and hallucination are perfect illustrations. The role played by skeptical possibilities is to extrapolate these kinds of errors, illusions and hallucinations, in order to construct a special kind of case represented in a skeptical scenario, where the possibility of error is massive and inescapable. There are significant differences here, so I will treat each of these cases in turn. ${ }^{13}$

Consider first cases of illusion: when we entertain an episode of illusion, our perception delivers results that an external observer can conclusively determine as false, for instance: when we see a stick partially immersed in the water, we (supposedly, as the argument goes) come to think that it is broken. The same thing goes when we look at something very closely, we see it double, (the argument goes) we come to think we are looking at two different things rather than one. Those are commonplace examples. Let us loosen our diet a bit and imagine a child that goes to a show of magic. She sees a magician cutting the assistant in half and genuinely comes to believe that the poor assistant is indeed cut in half. Now, in these cases, the deliverances of perception are misguiding, generating false results, but are at least partially based on genuine experiences - the beliefs that the stick is broken (when there is a stick), that there are two things here (when there is at least one thing), that the assistant is cut in half (when there is an assistant).

When we describe cases of illusion like that, we ignore the role that background and additional information perform, let alone the fact that people usually can move around and see things from different perspectives. The child, for instance, may ask her parents whether the assistant was really cut in half. By putting together new information such as the fact that magicians intend to entertain people through tricks, uses of light, distraction, stunts and of course stage ability; the child is able to correct her initial belief. In subsequent cases, given her access to new information from reliable sources, she is able to immediately assess her perceptual deliverances, for she is now in possession of a richer conceptual scheme. The other two cases admit similar construals: we of course usually know we are not looking at two different things when misperception, but these intermediary cases do not affect the main argument. 
we bring a piece of paper closer to our face - for we have additional and background information about the position of the object, about where it was standing in relation to our face a few moments ago, etc. We can move our faces away from it or close one eye. We certainly have seen stuff being immersed in water without breaking- we can pick up the stick and look at it out of the water - and we usually do not believe that the stick is broken. This is one way to read Austin's criticisms of the sense-data theorists' reconstruction of what it means to say 'the stick looks broken' and 'I am perceiving two pieces of paper'. Commenting on this last sentence, he writes: ${ }^{14}$

It is, I suppose, true that, if I know that I am suffering from double vision, I may say 'I am perceiving two pieces of paper' and, in saying this, not mean that there really are two pieces of paper there, in the sense that anyone not apprised of the special circumstances of the case would naturally and properly, in view of my utterance, suppose that I thought there were two pieces of paper. However, we may agree that in saying 'I am perceiving two pieces of paper', I may not mean - since I may know it to be untrue - that there really are two pieces of paper before me (Austin, 1962, p. 89).

A down-to-earth description of cases of illusions must allow for the fact that we are perfectly able to put ourselves, imaginatively or otherwise, in different positions. Through the use of memory and inference, we can remember we brought the paper closer to our eyes or that the stick was not broken a moment before or that when light goes through different mediums it suffers refraction or that people cut in half usually do not keep smiling and waving. What Noë $(2004,2012)$ calls our sensorimotor abilities plays an important role in plausible cases of illusion: we can move around, see things from different perspectives - and we understand how our perception of things remains the same or changes in relation to our movement. In normal cases, we would say we are rational when avoiding believing illusions are real, because it is entirely available to us to do so. We can see that there is something wrong with what is shown to us. ${ }^{15}$ Imagine someone sees for the first time the MüllerLyer illusion and forms the false perceptual belief that one line is longer than

14 On 'I am seeing a stick that looks broken', Austin's comment is that the use of such utterances do not imply that there is something being perceived that is broken, as Ayer (1940) suggests, something that should be characterized as a mind-dependent object immune to doubt, the sense-data.

15 One moral to be drawn from this discussion is that there is a demand of coherence for the maintenance of rationality in perception, and this coherence is reflected in the harmony between background knowledge, current perception and information added by the possible movements of our body. A consequence of this is that the richness of conceptual scheme a subject possesses enhances her rationality, in a way that different subjects, and the same subject through time, can be more or less rational. It is possible, for different people and for the same person at different times, to perceive the world with more or less accuracy. Notice that this appeal to coherentism is different from the crude coherentism I mentioned above: I am not saying coherence is sufficient for rationality, I am saying it is a regulative ideal, but there is a crucial qualification 
the other. She then decides to check for herself and draws the lines and the arrowheads. In this process she becomes aware that the lines do not have different sizes, even if they look (in a non-factive sense) that way. Thus, despite things looking (in a non-factive sense) so-and-so in normal cases of illusion, we know - or at least we generally can acquire the relevant knowledge - that things are not as they look and so we can avoid believing illusions are real. Once we flash out these details, we understand why we are willing to say that individuals entertaining episodes of illusion are (or can) be rational, for we are supposing that they can become aware that things are not what they seem in cases of illusions - which is generally true for down-to-earth cases. As I will reiterate bellow, this is not what happens in skeptical scenarios.

Unsurprisingly we would indeed refrain from ascribing rationality to individuals that inevitably fall for illusions of any kind. Imagine someone who inevitably believes that the stick is broken when immersed and believes it becomes straight all of a sudden when taken out of the water. A subject with these epistemic vices certainly could not put herself in an alternative position of imagining an object on a different angle or through the combination of different modalities (sight and touch and hearing and proprioception combined, for instance). As a consequence of such perceptual, imaginative and sensorimotor limitations, this person would always see, for instance, a soccer ball as a flat circle, and we would undeniably say that there is something wrong with her cognitive capacities. This person would believe that a piece of paper becomes two when it is close to her face, and that objects change size as we approach or move away from them. She would, so to speak, be trapped in the perspectival dimension of experience. There is no temptation whatsoever to claim that she is rational - further evidence for this is that her interaction with the world would be extremely impaired!

Consider now cases of hallucination. In normal cases, individuals that suffer from hallucinations sometimes entertain deviant experiences simultaneously with genuine cases of perception. Imagine someone sitting by the fire like Descartes in his meditations, and imagine also that our subject is very tired or stressed and almost asleep, and suddenly seems to hear someone calling her name. She has a very rich body of true beliefs about her environment (she sees the fire, knows it is night out there, has true beliefs about the color of the walls and what not), but entertains an imaginary sound not in the sense that she voluntarily imagines someone calling her name, but in 
the sense that no one was really calling her, she only seemed to hear a sound. Cases like this, wherein a subject entertains an auditory hallucination, suggest that hallucinating subjects do not conjure a whole world from the scratch, disregarding every input of available information - either presently received or inert in the background. Now, it seems that generally this kind of isolated occurrence is immediately accompanied by the discredit of the hallucinated sound, for it does not pass the test of coherence-one has sufficient background knowledge to rule out the possibility that there is someone really calling one's name. If this is the case, the low credibility enjoyed by such episodes of hallucination (sometimes called pseudohallucination) makes us refrain from saying that the individual is irrational. ${ }^{16}$

It is well documented that individuals suffering from Charles Bonnet syndrome - a condition that causes periodical visual hallucinations due to the gradual vision loss- are able to reliably discern intermittent hallucinations from veridical perception. In these cases, including ones in which the patient partially retains her perceptual capacities, there is no definitive impact on the ability to reason, what allows one to identify hallucinatory episodes through the context in which they occur and through the repetition of certain patterns (such as Lilliputian individuals, fancy and colorful clothes, bizarre augmentations of facial features, lack of sound and interaction with the hallucinating subject, etc.). This means that one retains a rich background body of true beliefs that is sufficient to discredit the hallucinations as they appear - for instance, one knows that people are generally more than a foot tall, and that noses do not magically change size, etc. This enables us to say that individuals who suffer from CBS, but not from additional mental and physical conditions, are far from being irrational, since they still manifest perceptual competences and retain episodic memory of successful perception, enabling them to discriminate perception from hallucination. ${ }^{17}$

16 We must be careful, however, when we say that an episode of hallucination does not "pass the test of coherence", since, on the view I am proposing, only perceptual (veridical) experiences are conceptually articulate. So hallucinations are not coherent neither incoherent with the rest of one's experience. We can counter this problem by saying that additional and background evidence are put to verify, maybe subpersonally, a subjunctive conditional such as: 'if I were perceiving a sound S, there would be a sound S coming from a certain source at a certain location, etc.', implying one is not actually perceiving a sound - what explains the low credibility of such hallucinatory states.

17 See Ffytche (2013) for an argument that there is fRMI evidence that hallucinations of individuals with CBS characterize the activation of the same areas in the brain as episodes of veridical visual perception. Macpherson (2013) argues that it is open to the disjunctivist to claim that this evidence does not confirm a common-kind view, as opposed to a disjunctivist one, on the basis that it presupposes that perception is the end result in a chain of events that occurs in the brain. The disjunctivist claims that perception is the chain itself, encompassing both the end result and the appropriate relation with the object of perception. Thus, the disagreement is in a philosophical level, not in an empirical one. Moreover, according to the view on 
Nevertheless, we can try to imagine someone who approaches the possibility of failing systematically to distinguish hallucination from perception. This would be the case of some patients with severe schizophrenia - they regard the voices they sometimes hear as external, sometimes aggressive and demanding. Their background knowledge fails them, their cognitive abilities are impaired. They certainly are not entirely irrational, for they still entertain genuine cases of perception, but in intermediate cases like this, we are less tempted to say they are perfectly rational. The fact that they fall short of being perfectly rational is not a problem to our present view, for we emphasized that rationality admits a continuum. We can try to think about more extreme cases - imagine an individual who is constantly hallucinating, in a way that his hallucinatory experiences largely overcome genuine perception. Call him Gonzo and imagine he is in a very long and intense mescaline trip. He would certainly fail to articulate most of his perceptual experiences, his memory and ability to reason projectively would be highly unreliable, his interactions with the world would be entirely unconventional to say the least. He would not only usually fail to achieve true perceptual beliefs about his surroundings, he would probably fail to assess his own immediate mental states as well. It seems that we hardly could ascribe Gonzo any sort of rationality if his hallucinations are like what the example suggests - but the key here is that, in such extreme cases, hallucinating subjects do not have their cognitive abilities intact despite the lack of factive perception, which is very different from more common hallucinations, such as pseudohallucinations and CBS hallucinations.

Now, it is safe to say that the rhetoric involved in constructing skeptical scenarios and the unexamined use of them often make it difficult to see what is going on - for skeptical hypotheses are introduced by saying 'imagine a brain in a vat whose perceptual inputs are being feed by a supercomputer simulating a normal environment etc.' and are later on just called 'BIV hypothesis' or 'Evil Genius hypothesis'. When we use a skeptical scenario like this, we assume some sort of continuity between those cases and everyday episodes of hallucination and illusion. And it does seem that there are some similarities between everyday cases and skeptical scenarios. The envatted brain has deviant experiences that consistently deliver false results: all of its beliefs

hallucination that Macpherson calls the strict disjunctive conception (Macpherson, 2013, p. 23), hallucinating subjects entertain experiences that lack phenomenal character, what precludes them from knowing by introspection of the hallucinatory episode alone that they are not perceiving what they hallucinate. However, as I say above, they can know that their hallucinatory episodes are not veridical with the aid of additional and background knowledge. 
about the external world are false, including the ones about its non-existent body and its personal history and so on. In this sense, the envatted brain's case is similar to a case of hallucination, with the significant difference that the envatted brain never entertains veridical beliefs about its surroundings - it is unable, by the very way the scenario is set up, to use its background knowledge to discredit its deviant experiences. Differently, individuals who suffer from hallucinations sometimes have genuine, true beliefs mixed with false ones, and are sometimes able to separate them. Only in extreme cases, like Gonzo's, individuals approach the possibility of systematically entertaining false beliefs - but this case is still different from a skeptical scenario, for Gonzo certainly has bits of memory and sparse episodes of genuine experiences (imagine he remembers where to buy mescaline). We are inclined to say that individuals in normal cases of hallucinations are still rational, for they are able to discern genuine perception from deviant experiences. But we are less inclined to say that Gonzo is rational, since his cognitive abilities are in general unreliable. Skeptical scenarios demand us to think of subjects who are systematically entertaining false perceptual beliefs and have perfectly functional cognitive abilities - they can reason properly, they can remember stuff, they are careful when considering the available evidences, etc. (otherwise we would not even be tempted to say that they could be rational in the first place). Therefore, there is something clearly amiss here: to the extent that such scenarios trade upon cases of hallucination, they do not behave like normal cases, and this difference is fundamental to ascriptions of rationality. Hence they show us nothing about what is to be rational.

Now, the envatted brain is too, in a way, being deceived by illusions. For when we talk about illusions we sometimes imply that someone has the intent to mislead someone else (think about the magician), or maybe that something was designed with such intent (think about Müller-Lyer illusion). Not by accident, the information fed to the brain in a vat is always manipulated by some entity: an Evil Genius (as in the classic Cartesian example) or an evil scientist commanding a supercomputer or something along the same lines. But the key in the skeptical scenarios is that there is no way for the subject to avoid being deluded, there is nothing she can do. When we see a magic trick we know, by the context we are in, that the trick is not really as it appears. The same thing goes for Müller-Lyer lines, we can draw the lines ourselves and see they are about the same size. And here is the discrepancy, for this is not what happens in a skeptical scenario. Maybe the term 'skeptical scenario' is itself misleading, for a scenario has its limits - if one wanders around a 
genuine scenario, one eventually sees the end of it. But in a skeptical scenario, there is nothing one can do to get out, to avoid believing falsely. So, in the precise sense that illusions are unavoidable for the envatted brain, the subject in such scenarios is like the person who always mistakes a ball for a flat circle or thinks that the stick magically turns broken and straight and broken again - as if she were trapped on the perspectival aspect of perception. Note, however, that the way the case is described suggests that the envatted brain has perfectly functioning cognitive capacities (what would tempt us to say it is epistemically responsible at least). Nevertheless, the idea of cognitive capacities functioning flawlessly is in clear contrast with the idea of an individual being systematically deceived by illusions. In this case too, we have a fundamental difference between genuine cases of illusion and what skeptical scenarios invite us to consider. This is why such scenarios show us nothing about what is to be rational.

\section{Concluding remarks}

I expect to have shown that, from the acceptance of a strong version of epistemological disjunctivism, a commitment with a transformative view of rationality arises naturally. This means that envatted brains could not be rational, and this consequence seems to be in tension with widely shared assumptions. Is this consequence truly problematic? Apparently we can conceive of situations in which brains in vats avoid inferential pitfalls and are careful when assessing the available evidence. But does this show that rationality can be achieved independently of the relation one holds with the environment? I do not think so. My arguments in the last section are intended to highlight that skeptical scenarios are not mere extrapolations of genuine cases of illusion and hallucination: skeptical scenarios rely on the confusing idea of an individual being systematically deceived and manifesting irreproachable cognitive abilities. When we evaluate a person's rationality in normal cases of illusion and hallucination, either we are inclined to say the individual is rational because her cognitive abilities are working properly and she is able to discredit the deviant experiences (some cases of Charles Bonnet syndrome, pseudohallucinations, immersing a stick in water, etc.), or we are inclined to say the individual fails to be rational because she is unable to discredit deviant experiences (Gonzo's case, some schizophrenics, the person who is trapped in the perspectival aspect of perception).

Philosophical tradition has ignored the implicit discrepancy between, on the one hand, what skeptical scenarios invite us to consider and, on the 
other, everyday attributions of rationality. As a consequence, it has put more weight on the idea that we are inclined to say that envatted brains could be rational, instead of questioning whether it makes sense to ascribe rationality to individuals in skeptical scenarios. The theoretical justification for this is in part due to the wide and unscrutinized acceptance of additive views on rationality, as Boyle puts it, - yet the underlying non-disjunctivist view on perception also plays a part. Now, if the construction of skeptical scenarios is in conflict with our intuitions about the rationality of individuals in everyday cases of hallucinationsand illusion, it is not surprising that we could not know what to say when we take a closer look on skeptical hypotheses. The upshot is that skeptical scenarios show us nothing about our rationality, in particular, they do not testify against our conclusion that it is only possible for an individual to be rational about her environment if she entertains genuine cases of perception. The core of my critique to the construction of skeptical scenarios is similar to an idea brilliantly described by Austin:

If we have made sure it's a goldfinch, and a real goldfinch, and then in the future it does something outrageous (explodes, quotes Mrs. Woolf, or what not), we don't say we were wrong to say it was a goldfinch, we don't know what to say. Words literally fail us: 'What would you have said?' 'What are we to say now?' 'What would you say?'(Austin, 1946, p. 88).

Finally, I think the results we reached here suggest important considerations on the value and the limits of using skeptical scenarios (and maybe, more generally, science fiction) in doing philosophy. Moreover, and this should be clear, I did not intend to convince anyone unwilling to accept a disjunctivist conception of perceptual knowledge, but, as the discussion advances, the motivations and advantages of this view may be a good starting point to revisit some traditional and unquestioned conceptions.

\section{References}

AUSTIN, J. L. (1946) “Other Minds”. In: URMSON, J. O.; WARNOCK, G. J. (eds.). J.L. Austin: Philosophical Papers. London: Oxford University Press, 1970. pp. $76-$ 116.

AUSTIN, J. L. "Sense and Sensibilia". London: Oxford University Press, 1962.

AYER, J. "The Foundations of Empirical Knowledge". London: The MacMillian Press Ltd, 1940.

BOYLE, M. "Additive Theories of Rationality: a Critique". European Journal of Philosophy, Forthcoming. Available on: http://nrs.harvard.edu/urn-3:HUL. InstRepos:8641840. 
BREWER, B. "Perception and Reason". Oxford: Oxford University Press, 2003. BURGE, T. "Individualism and Self-Knowledge". Journal of Philosophy, Vol. 85, pp. 649-663, 1988.

FFYTCHE, D. H. "The Hallucinating Brain: Neurobiological Insights into the Nature of Hallucinations". In: MACPHERSON, F.; PLATCHIAS, D. (eds.), 2013. pp. 45-64. GENDLER, T. S.; HAWTHORNE, J. (eds.). "Perceptual Experience". Oxford: Oxford University Press, 2006.

KORNBLITH, H. “On Reflection”. Oxford: Oxford University Press, 2012.

MACPHERSON, F. "The Philosophy and Psychology of Hallucination: An Introduction". In: MACPHERSON, F.; PLATCHIAS, D. (eds.), 2013. pp. 1-38.

MACPHERSON, F.; PLATCHIAS, D. (eds.). "Hallucination: Philosophy and Psychology". Cambridge: The MIT Press. 2013.

MARTIN, M. G. F. “On Being Alienated”. In: GENDLER, T. S.; HAWTHORNE, J. (eds.), 2006. pp. 354-410.

MCDOWELL, J. "Meaning Knowledge and Reality". Cambridge, Massachusetts: Harvard University Press, 1998.

MCDOWELL, J. "Mind and World". Cambridge: Harvard University Press, 1994.

MCDOWELL, J. "Perception as a Capacity for Knowledge". Milwaukee: Marquette University Press, 2011.

MCDOWELL, J. "Singular Thoughts and the Extent of Inner Space". In: MCDOWELL, J. 1998. pp. 228-259.

NOË, A. "Action in Perception". Cambridge, Massachusetts: MIT Press, 2004.

NOË, A. "Varieties of Perception". Cambridge, Massachusetts: Harvard University Press, 2012.

NOZICK, R. "Philosophical Explanations". Cambridge, Massachusetts: Harvard University Press, 1981.

PEACOCKE, C. "A Study of Concepts". Cambridge: MIT Press, 1992.

PEACOCKE, C. "Transcendental Arguments in the Theory of Content". Oxford: Oxford University Press, 1989.

PRITCHARD, D. "Epistemological Disjunctivism". Oxford: Oxford University Press, 2012.

PUTNAM, H. "Reason, Truth and History". Cambridge: Cambridge University Press, 1981.

SELLARS, W. "Empiricism and the Philosophy of Mind". Cambridge, Massachusetts: Harvard University Press, 1997.

SHI, Y.; YOKOYAMA, S. "Molecular analysis of the evolutionary significance of ultraviolet vision in vertebrates". Proceedings of the National Academy of Sciences, Vol. 100, Nr. 14, pp. 8308-8313, 8 July 2003. 